\title{
LOW-PRESSURE DISCHARGE PLASMA TREATMENT OF AQUEOUS SOLUTIONS WITH Mn, Cr AND Fe
}

\author{
Oleksandr Pivovarov ${ }^{1}$, Tetiana Derkach ${ }^{2,}{ }^{*}$, Margarita Skiba $^{1}$
}

https://doi.org/10.23939/chcht13.03.317

\begin{abstract}
The effect of low-pressure glow discharge on the formation of peroxide and the degree of oxidation of $\mathrm{Mn}, \mathrm{Cr}$ and $\mathrm{Fe}$ was studied in the aqueous solutions of different compounds. The plasma treatment causes the reduction of $\mathrm{Mn}$ (VII) through $\mathrm{Mn}(\mathrm{IV})$ to $\mathrm{Mn}(\mathrm{II}), \mathrm{Cr}(\mathrm{VI})$ to $\mathrm{Cr}$ (III) and oxidation of $\mathrm{Fe}(\mathrm{II})$ to $\mathrm{Fe}(\mathrm{III})$. Among other reactive species, peroxide formed under the action of plasma treatment takes an active part in redox reactions. The concentration of peroxide usually increases with treatment time, but its presence is detected only after completion of active redox processes.
\end{abstract}

Keywords: low-pressure glow discharge plasma treatment, redox reactions, peroxide formation, reduction, oxidation.

\section{Introduction}

The application of plasma discharge to treat liquid solutions is characterised by high diversity. In particular, in mining and metallurgy, plasma technologies are used for material processing [1], intensification of leaching of noble metals from ore concentrates [2], obtaining fullerenes and nanopowders [3], etc. In analytical chemistry, plasma discharges are utilised in the course of sample preparation, as microsized sources of emission for analysis of water solutions, as ionisation sources for mass spectrometry, as well as for enhancement of an analytical signal [4-6]. In the chemical industry, there are known examples of modification of polymer surfaces, cellulose bleaching and chemical synthesis. Plasma-aided blood coagulation, tissue ablation, wound healing and sterilisation are among typical medical applications of the plasma discharge [7].

Environmental remediation and wastewater treatment are reckoned among the most critical applications of

\footnotetext{
${ }^{1}$ Department of Inorganic Substances and Ecology, Ukrainian State University of Chemical Technology,

8, Gagarina Ave., 49005 Dnipro, Ukraine

${ }^{2}$ Department of Industrial Pharmacy, Kyiv National University of Technologies and Design,

2, Nemirovicha-Danchenko St., 01011 Kyiv, Ukraine

*derkach.tm@knutd.edu.ua

(C) Pivovarov O., Derkach T., Skiba M., 2019
}

plasma technologies [8]. The wastewater releasing from industrial plants or households often contains harmful elements and compounds, in many cases of organic origin. So, it is vital to remove them from the Earth biosphere.

Various methods of water treatment, such as physical, biological and chemical, have been developed during centuries. Physical and biological processes are usually low cost but, in some cases, they do not efficiently remove some kinds of pollutants, especially organic compounds. Also, the biological treatment is typically much slower than other processes. Chemical methods are based on direct oxidation via reactants with high oxidation potential such as chlorine, ozone, potassium permanganate, etc. However, the use of such reagents is limited due to the formation of potentially hazardous byproducts (for example halogenated in case of chlorine treatment). The ozonation is very efficient but the most expensive method of water treatment.

Plasma treatment realised in various forms of plasma discharge is a very effective attractive alternative to the methods of solution treatment mentioned above. Plasma discharge was successfully used to treat wastewaters contaminated with herbicides/pesticides, decompose pharmaceuticals, surfactants, sulfonol, phenol and textile dyes [9-12]. Many of the researches have focused on the decomposition of organic compounds which are key contaminants in source water. Another critical application is to remove ions of heavy metals contained in wastewaters [13].

The discharge releases high energy into a liquid phase and generates highly reactive species. Plasma in liquids can be produced in devices with different electrode configurations (a corona discharge over the surface solution, a contact glow discharge, a pulsed streamer discharge in or above solution, dielectric barrier discharge, gliding arc) and voltage regimes (DC pulsed, DC nonpulsed, AC, HF, etc.) [14]. A diversity of configurations promotes a variety of applications.

The plasma discharge causes various physical and chemical effects in the treated medium. Among physical phenomena, diffusion and advection, local heating, surface tension, secondary emission and charge deposition, sputtering and evaporation can be listed as 
typical for plasma discharges in solutions. Processes of surface electrolysis, hydrolysis, charge transfer, electronion and ion-ion recombinations, reduction-oxidation (redox) reactions, and collision relaxation take simultaneously place in gas-plasma and liquid regions, as well as the gas-liquid interface, that determines the complexity of chemical effects.

As was classified in [15], three different species of particles take part in the processes of plasma treatment. The gaseous parent species are determined by the ambient gas. For a plasma reactor operated in air, for example, these species are molecules of $\mathrm{O}_{2}, \mathrm{~N}_{2}$, and $\mathrm{H}_{2} \mathrm{O}$. The primary species are being directly formed in the burning discharge. They include various highly reactive particles, such as radicals, high energetic electrons, excited ions, molecules, and photons. Further, the secondary species result from reactions which are not directly formed in the discharge but involve either primary species or primary and parent species. The primary species quickly appear but are not stable. The secondary species result from chemical reactions and, at least, some of them are more stable and thus are of interest for practical applications.

The chemical effects induced by the discharge and concerning the solutes depend on the formed species. Essential reactive species are hydroxyl radicals which are characterised by a high oxidation potential. Other strong oxidation reagents produced by plasma are oxygen radicals, ozone and hydrogen peroxide. A synergic effect of more oxidation reagents is possible as was discussed in [16] where simultaneous reduction of $\mathrm{Cr}(\mathrm{VI})$ and oxidation of As(III) were observed in wastewaters under plasma treatment.

The formation of peroxide in water and aqueous solution has been observed in many works [17-19]. There is a consensus that peroxide results from various reactions between chemically reactive particles produced by a plasma discharge and thus is a secondary species of plasma treatment. However, observations of its behaviour are less definite. In some cases, the peroxide concentration is a linear function of plasma treatment time. Sometimes, a clear time-delay is observed in the peroxide emergence. In other cases, the peroxide concentration remains depressive over the observation time.

It is well known that peroxide can participate in redox reactions and affect the oxidation state of metallic elements in various compounds. Therefore, it is of practical interest to study the rates of peroxide formation and consumption in the course of redox reactions in different aqueous solutions. The paper goal is to research the concentrations of peroxide and ions that contain metals ( $\mathrm{Fe}, \mathrm{Cr}$ and $\mathrm{Mn}$ ) as a function of plasma treatment time in correlations with different $\mathrm{pH}$ and to reveal any relationships between peroxide and oxidation level of metallic elements.

\section{Experimental}

A barrel-type glass reactor with inside diameter of $30 \mathrm{~mm}$ and $180 \mathrm{~mm}$ in height was used for plasma treatment. Stainless steel electrodes were made of the wire rod of $4 \mathrm{~mm}$ in diameter. The plasma discharge used is reckoned in a low-pressure glow discharge type. One of the electrodes (cathode), being immersed in the studied solution, was placed in the lower part of the reactor. Another electrode (anode) was set at an adjustable distance of $5-7 \mathrm{~mm}$ above the solution surface. Air pressure in the reactor was held constant by a vacuum pump at a level of $12-15 \mathrm{kPa}$. The discharge was generated by applying a DC high voltage ( 500-700 V) between the metal anode and water solution. The discharge current varied between 10 and $100 \mathrm{~mA}$. Optimal values of the discharge current and air pressure were determined and applied to each treated solution.

The volume of the solution in the reactor was $50 \mathrm{ml}$. The time of plasma treatment varied from 0.1 to 30 min. Continuous circulation of cold water was maintained in an outer jacket to cool down the reaction mixture. The initial temperature of the solution was $293 \mathrm{~K}$; it elevated to $303-308 \mathrm{~K}$ in the course of plasma treatment. Evaporation of the solution was observed during the discharge process. However, the lowering in solution level was negligible at the time of the experiment. The compositions of as-treated solutions, as well as crucial treatment regimes, are shown in Table 1.

The method of flame atomic absorption spectroscopy (FAAS) was used to measure the total content of metals ( $\mathrm{Cr}, \mathrm{Fe}$ or $\mathrm{Mn}$ ) in filtered solutions. The quantification of FAAS was performed with the use of certified reference materials produced by O. V. Bogatsky Physics and Chemistry Institute (Odessa, Ukraine). The concentration of $\mathrm{Mn}^{2+}$ ions in solutions was measured by the Volhard method.

The solute concentrations of $\mathrm{Fe}(\mathrm{III}), \mathrm{Cr}(\mathrm{VI})$ and $\mathrm{Mn}$ (VII) were determined by spectrophotometry. Chemical methods controlled the Mn(IV) level. The completeness of Mn(VII)-to-Mn(II), Cr(VI)-to-Cr(III) and $\mathrm{Fe}(\mathrm{II})-$ to-Fe(III) transformations was estimated by a combination of FAAS and spectrophotometry.

The total content of oxidisers, including peroxide, was measured in the plasma-treated solutions by an iodometric titration method. Also, the content of hydrogen peroxide was separately determined by either permanganatometry or spectrophotometry using the reaction of $\mathrm{H}_{2} \mathrm{O}_{2}$ with ions that contain $\mathrm{Ti}(\mathrm{IV})$ by the analysis of the maximum absorbance of the yellow $\left[\mathrm{TiO} \cdot \mathrm{H}_{2} \mathrm{O}_{2}\right]^{2+}$ 
complex at the wavelength of $410 \mathrm{~nm}$. The difference between the total oxidiser content and peroxide content studied by different methods was used to consider the influence of particles of different types on the reaction course.

\section{Results and Discussion}

\subsection{Solutions with $\mathrm{Mn}$}

The results of plasma treatment of solutions that contain $\mathrm{Mn}$ in different oxidation states are shown in Fig. 1. A pronounced decrease of the total $\mathrm{Mn}$ concentration is observed in two more concentrated solutions after 2-4 min of treatment (Fig. 1a). This effect is accompanied by intense precipitation. With increasing treatment time, the precipitates interact with active reducers accumulated in the solution and start to dissolve increasing the Mn concentration.

The total Mn concentration in two diluted solutions is less changeable (Fig. 1a). A small amount of precipitates is observed in these two solutions after more prolonged plasma treatment.
All changes of $\mathrm{pH}$ with treatment time also depend on the Mn concentration (Fig. 1c). A clear local maximum on the $\mathrm{pH}$ curves with simultaneous decolouration of the solutions is observed in diluted solutions with 37 and $58 \mu \mathrm{mol} / \mathrm{l} \mathrm{Mn}$ after 1-3 min of treatment. With a further increase of treatment time, the $\mathrm{pH}$ values start to decrease from 8.7 to 3.1 with concurrent precipitation.

For more concentrated solutions, such as 173 and $335 \mu \mathrm{mol} / \mathrm{l}$, initial $\mathrm{pH}$ growth and its follow-up reduction are more temperate and peaks on the $\mathrm{pH}$ curves are less pronounced.

Peroxide $\mathrm{H}_{2} \mathrm{O}_{2}$ appears in the solution in the course of plasma treatment (Fig. 1b). For diluted solutions, this process starts very quickly, just after some seconds of plasma treatment. For concentrated solutions, there is a noticeable time delay in $\mathrm{H}_{2} \mathrm{O}_{2}$ formation. The value of such a delay usually increases with $\mathrm{Mn}$ concentration.

The comparison of Mn (Fig. 1a) and $\mathrm{H}_{2} \mathrm{O}_{2}$ (Fig. 1b) curves allows one to conclude that peroxide starts to accumulate actively in the solution only after completion of the process of $\mathrm{Mn}(\mathrm{VII})$ reduction. Evidently, this time depends on the initial Mn concentration. It is tiny in diluted samples and varies between 6 and $10 \mathrm{~min}$ in concentrated solutions.

Table 1

Plasma treatment regimes of aqueous solutions that contain $\mathrm{Mn}, \mathrm{Cr}$ and $\mathrm{Fe}$ in different oxidation states

\begin{tabular}{|c|c|c|c|c|c|c|}
\hline Soluted compound & Metal & $\begin{array}{c}\text { Initial } \\
\text { valence }\end{array}$ & $\begin{array}{c}\text { Metal concentration, } \\
\mu \text { mol/ }\end{array}$ & $\begin{array}{c}\text { Discharge } \\
\text { current, mA }\end{array}$ & $\begin{array}{c}\text { Air pressure, } \\
\text { kPa }\end{array}$ & $\begin{array}{c}\text { Treatment } \\
\text { time, min }\end{array}$ \\
\hline $\mathrm{KMnO}_{4}$ & $\mathrm{Mn}$ & VII & $37-336$ & $15-25$ & 15 & $0-15$ \\
\hline $\mathrm{K}_{2} \mathrm{Cr}_{2} \mathrm{O}_{7}$ & $\mathrm{Cr}$ & VI & 250 & 25 & 12 & $0-20$ \\
\hline $\mathrm{K}_{2} \mathrm{CrO}_{4}$ & $\mathrm{Cr}$ & VI & $250-700$ & 25 & 12 & $0-20$ \\
\hline $\left.\mathrm{KCr}_{2} \mathrm{SO}_{4}\right)_{2} \cdot 6 \mathrm{H}_{2} \mathrm{O}$ & $\mathrm{Cr}$ & III & 280 & 25 & 12 & $0-20$ \\
\hline $\mathrm{FeSO}_{4}$ & $\mathrm{Fe}$ & II & 2850 & 25 & 13 & $0-12$ \\
\hline $\mathrm{Fe}_{3}\left(\mathrm{SO}_{4}\right)_{2}$ & $\mathrm{Fe}$ & III & 2500 & 25 & 13 & $0-12$ \\
\hline
\end{tabular}
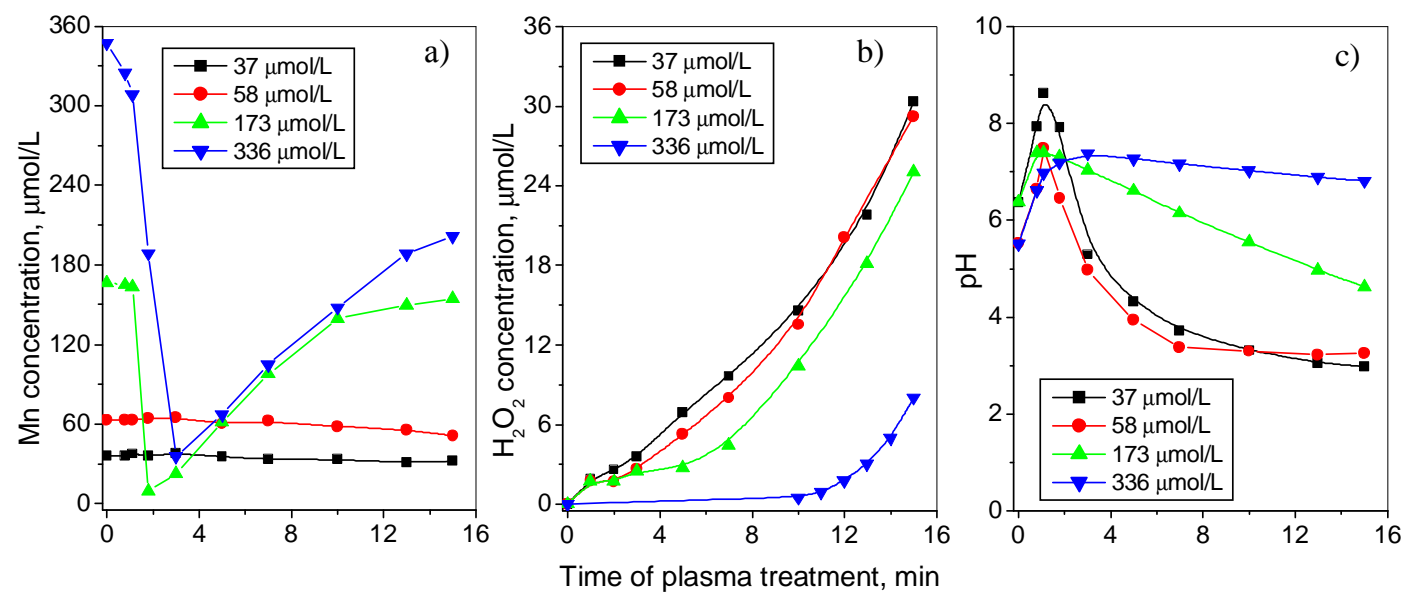

Fig. 1. Concentrations of $\mathrm{Mn}(\mathrm{a}), \mathrm{H}_{2} \mathrm{O}_{2}$ (b), and $\mathrm{pH}$ (c) in aqueous solutions of $\mathrm{KMnO}_{4}$ with different $\mathrm{Mn}$ concentrations as a function of plasma treatment time 


\subsection{Solutions with $\mathrm{Cr}$}

Redox effects under plasma treatment become apparent in changes of the oxidation level of $\mathrm{Cr}$ in compounds. Aqueous solutions of potassium dichromate and bichromate were treated with a low-pressure plasma discharge and the results obtained are shown in Fig. 2. Approximately half of the $\mathrm{Cr}(\mathrm{VI})$-containing ions in chromate solutionis reduced to $\mathrm{Cr}$ (III) for 2 min while the reduction process is completed for approx. $18 \mathrm{~min}$ of the plasma treatment (Fig. 2a). The formation of peroxide in chromate and dichromate solutions accelerates after completing the $\mathrm{Cr}(\mathrm{VI})$ reduction process (Fig. 2b). In particular, the delay in $\mathrm{H}_{2} \mathrm{O}_{2}$ formation for the most concentrated $700 \mu \mathrm{mol} / 1 \mathrm{~K}_{2} \mathrm{CrO}_{4}$ is observed for more than $16 \mathrm{~min}$.

When a solution of chromic potassium alum was treated, no visible changes in the solution and the oxidation level of $\mathrm{Cr}$ (III) were observed. The formation of $\mathrm{H}_{2} \mathrm{O}_{2}$ proceeds with a high rate without any delay (Fig. 2b). Therefore, ions with $\mathrm{Cr}(\mathrm{VI})$ seem to react actively with peroxide while $\mathrm{Cr}(\mathrm{III})$ ions remain inactive in plasma-treated solutions.

The plasma treatment of solutions with fixed started concentrations of $\mathrm{Cr}(\mathrm{VI})$ and $\mathrm{Cr}(\mathrm{III})$ for 5-10 min lead to decreasing hydrogen index by at least four units to $\mathrm{pH}=2.8$ (Fig. 2c). The shapes of $\mathrm{pH}(t)$ were almost independent of the initial $\mathrm{Cr}$ concentrations. Evidently, the observed decrease of $\mathrm{pH}$ is mainly caused by an interaction of plasma with water molecules as follows from the shape of the $\mathrm{pH}(t)$ curve for distilled water. Plasma discharge, interacting with a liquid phase, generates particles with strong acid properties. As a result of further recombination processes, peroxide, which is detected in all studied solutions, is formed.

\subsection{Solutions with $\mathrm{Fe}$}

Taking in mind different behaviour of ions containing $\mathrm{Cr}(\mathrm{VI})$ and $\mathrm{Cr}(\mathrm{III})$ in plasma treated solutions, both $\mathrm{Fe}(\mathrm{III})$ and $\mathrm{Fe}$ (II) sulphates were studied in experiments with Fe-containing solutions. The concentration of $\mathrm{Fe}(\mathrm{III})$ ions quickly increases in $\mathrm{FeSO}_{4}$ within the first minute of plasma treatment but remains unchanged in $\mathrm{Fe}_{3}\left(\mathrm{SO}_{4}\right)_{2}$ during the whole period of observation (Fig. 3a). Simultaneously the concentration of $\mathrm{Fe}(\mathrm{II})$ ions drops to zero in $\mathrm{FeSO}_{4}$ solutions, and this ion is never observed in plasma-treated $\mathrm{Fe}_{3}\left(\mathrm{SO}_{4}\right)_{2}$.

The form into which $\mathrm{Fe}(\mathrm{II})$ is transformed under the plasma action depends on the initial $\mathrm{pH}$ of a $\mathrm{FeSO}_{4}$ solution. The quantitative transition of $\mathrm{Fe}(\mathrm{II}) \leftrightarrow \mathrm{Fe}(\mathrm{III})$ without the formation of a solid phase is carried out at $\mathrm{pH}=1.6$. The oxidation rate of $\mathrm{Fe}(\mathrm{II})$ slightly increases with increasing $\mathrm{pH}$ from 1.6 to 2.9. However, at $\mathrm{pH}>2.2$, precipitation of $\mathrm{Fe}(\mathrm{OH})_{3}$ occurs. Due to partial deposition, the total concentration of $\mathrm{Fe}$ begins to decrease after 13 min treatment of solutions with $\mathrm{pH}>2.2$.

The peroxide concentration generated by the plasma discharge (Fig. 3b) behaves similarly as in solutions of manganese compounds (Fig. 1b) and $\mathrm{Cr}$ (Fig. 2b) ions. The $\mathrm{H}_{2} \mathrm{O}_{2}$ concentration in general increases with treatment time. In $\mathrm{FeSO}_{4}$ solutions, some time-delay is observed in the peroxide formation which correlates well with the time of active oxidation of $\mathrm{Fe}(\mathrm{II})$ to-Fe(III). On the contrary, no delay is detected in $\mathrm{Fe}_{3}\left(\mathrm{SO}_{4}\right)_{2}$ solutions where no plasma-induced redox processes occur.
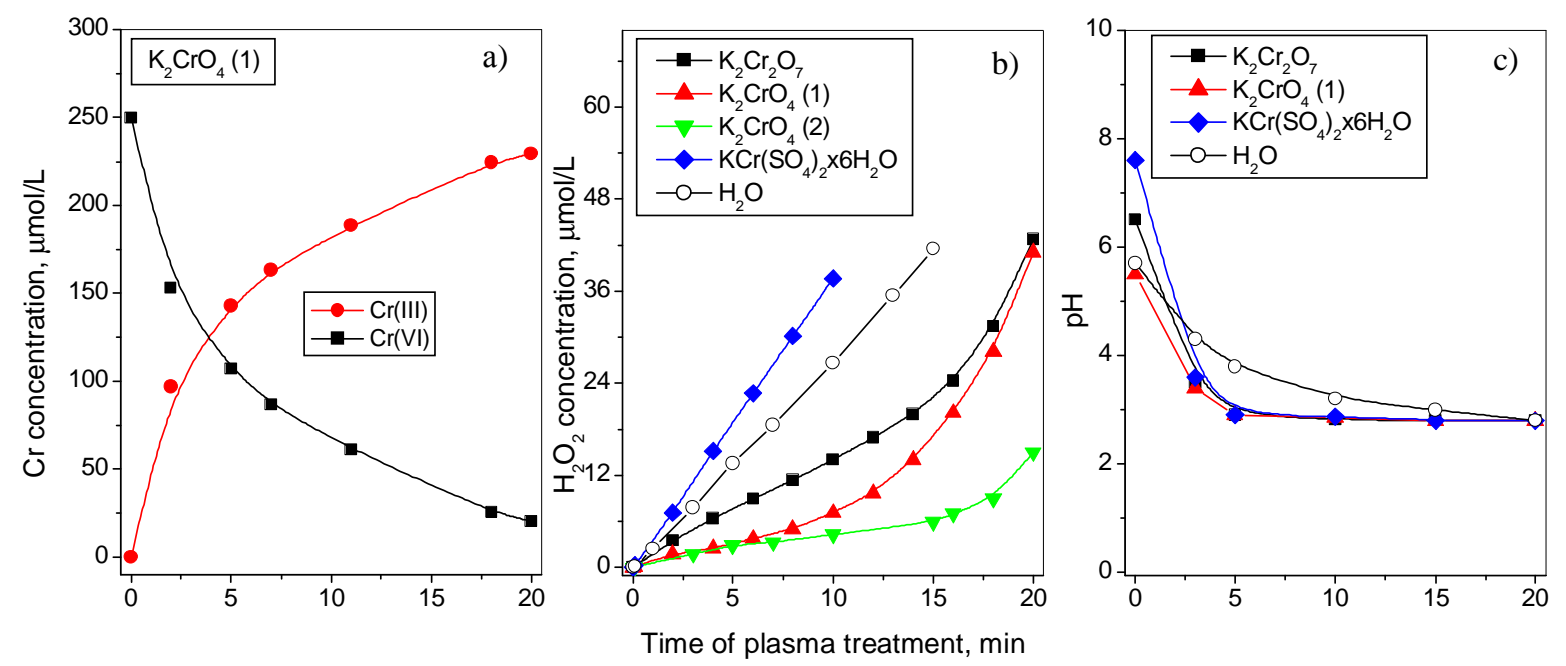

Fig. 2. Concentrations of $\mathrm{Cr}(\mathrm{a}), \mathrm{H}_{2} \mathrm{O}_{2}$ (b), and $\mathrm{pH}$ (c) in aqueous solutions of $\mathrm{K}_{2} \mathrm{Cr}_{2} \mathrm{O}_{7}(250 \mu \mathrm{mol} / \mathrm{l} \mathrm{Cr}), \mathrm{K}_{2} \mathrm{CrO}_{4}(1-250 \mu \mathrm{mol} / \mathrm{l} \mathrm{Cr}, 2-700 \mu \mathrm{mol} / / \mathrm{lr})$ and $\mathrm{KCr}\left(\mathrm{SO}_{4}\right)_{2} \cdot 6 \mathrm{H}_{2} \mathrm{O}(280 \mu \mathrm{mol} / \mathrm{l} \mathrm{Cr})$ as a function of time of plasma treatment 

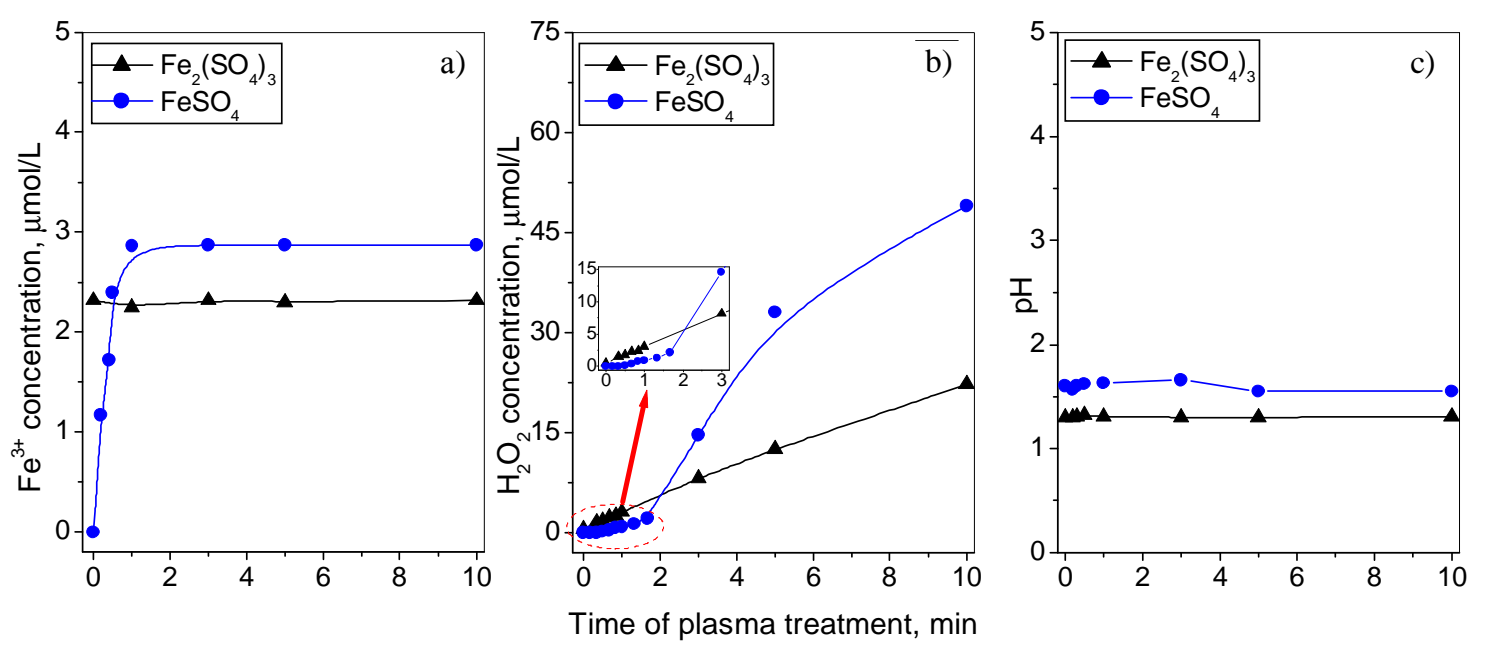

Fig. 3. Concentrations of $\mathrm{Fe}(\mathrm{III})(\mathrm{a}), \mathrm{H}_{2} \mathrm{O}_{2}$ (b) and $\mathrm{pH}$ (c) in aqueous solutions of $\mathrm{FeSO}_{4}(\mathrm{pH}=1.3)$ and $\mathrm{Fe}_{2}(\mathrm{SO} 4)_{3}(\mathrm{pH}=1.6)$ with $2.85 \mathrm{mmol} / \mathrm{l} \mathrm{Fe}$ and $2.5 \mathrm{mmol} / \mathrm{l} \mathrm{Fe}$, respectively, as a function of time of plasma treatment

\subsection{Peroxide Formation}

Peroxide plays an essential role in plasma-induced redox reactions. While $\mathrm{OH}$ radicals have higher oxidation potential, however, they are unstable and easily decay in reactions with one another or hydrogen atoms. There is a consensus that peroxide is formed in plasma-treated solutions due to secondary reactions occurring with the participation of plasma-induced primary species. The basic processes of formation of primary active particles begin in the gas phase [20]. After discharge ignition, collisions of charged particles and gas molecules lead to the formation of several radicals and active species like solvated electrons $\left(e_{e q}\right), \mathrm{OH}, \mathrm{H}, \mathrm{O}, \mathrm{O}_{3}$ in the gas phase. These radicals may then react with themselves in a gas phase and with other particles in a thin subsurface layer of a liquid. The charged-particle bombardment of the solution surface causes the transfer of neutral particles to the plasma zone. Therefore, the reaction types and rates are dependent on gas medium and characteristics of a liquid phase, such as $\mathrm{pH}$.

Reactions with the participation of $\mathrm{OH}^{*}$ radicals are usually considered as the main source of $\mathrm{H}_{2} \mathrm{O}_{2}$ formation [18]:

$$
\mathrm{OH}^{\bullet}+{ }^{\circ} \mathrm{OH} \rightarrow \mathrm{H}_{2} \mathrm{O}_{2}
$$

On the other hand, $\mathrm{OH}^{\circ}$-radicals, as well as solvated electrons $e_{e q}$ can simultaneously react with the hydrogen peroxide and thus decrease its concentration in the solution:

$$
\begin{aligned}
\mathrm{OH}^{\bullet}+\mathrm{H}_{2} \mathrm{O}_{2} & \rightarrow \mathrm{HO}_{2}{ }^{\circ}+\mathrm{H}_{2} \mathrm{O} \\
\mathrm{OH}^{\circ}+\mathrm{H}_{2} \mathrm{O}_{2} & \rightarrow \mathrm{O}_{2}+\mathrm{H}_{2} \mathrm{O} \\
e_{e q}+\mathrm{H}_{2} \mathrm{O}_{2} & \rightarrow \mathrm{OH}^{\circ}+\mathrm{OH}^{-}
\end{aligned}
$$

Therefore, the relationship between the rates of reactions (1) and (2-4) can determine the behaviour of peroxide concentration [12]. Such a course of events seems to describe the simplest situation, but it does not always fit the experimental observations. For examples, sometimes the measured rate of formation of $\mathrm{OH}^{*}$ radicals was much lower than the rate of formation of $\mathrm{H}_{2} \mathrm{O}_{2}$ [18]. As found in [21], $\mathrm{OH}^{\circ}$ radicals play an important role in the $\mathrm{H}_{2} \mathrm{O}_{2}$ formation under nitrogen and helium atmosphere where the reaction of $\mathrm{OH}^{\circ}$-radicals dimerisation dominates.

In air with water vapour, $\mathrm{OH}^{\circ}$-radicals have a limited direct effect, and the most probable mechanisms include hydrogen atoms reacting with $\mathrm{HO}_{2}$ and process of $\mathrm{HO}_{2}$ dimerisation:

$$
\begin{gathered}
\mathrm{H}^{*}+\mathrm{HO}_{2}^{\cdot} \rightarrow \mathrm{H}_{2} \mathrm{O}_{2} \\
\mathrm{HO}_{2}+\mathrm{HO}_{2} \rightarrow \mathrm{H}_{2} \mathrm{O}_{2}+\mathrm{O}_{2}
\end{gathered}
$$

Also, excited oxygen molecules can contribute to the formation of $\mathrm{H}_{2} \mathrm{O}_{2}$ in the solution in an air discharge by the following reactions $[21,30]$ :

$$
\begin{gathered}
\mathrm{H}+\mathrm{O}_{2} \rightarrow \mathrm{HO}_{2} \\
\mathrm{O}_{2}+e \rightarrow \mathrm{O}_{2}^{-} \\
\mathrm{O}_{2}^{-}+\mathrm{H}^{+} \leftrightarrow \mathrm{HO}_{2} \\
\mathrm{HO}_{2}+e \rightarrow \mathrm{HO}_{2}^{-} \\
\mathrm{HO}_{2}^{-}+\mathrm{H}^{+} \rightarrow \mathrm{H}_{2} \mathrm{O}_{2} \\
\mathrm{HO}_{2}+\mathrm{H} \rightarrow \mathrm{H}_{2} \mathrm{O}_{2}
\end{gathered}
$$

When accumulating in the course of chemical transformations, hydrogen peroxide tends to polymerise forming hydrogen polyoxides [22]. In general, this process can be described as follows:

$$
(n-1) \mathrm{H}_{2} \mathrm{O}_{2} \rightarrow \mathrm{HO}_{n} \mathrm{H}+(n-2) \mathrm{H}_{2} \mathrm{O}
$$

The action of plasma on electrolyte solutions initiates oxidation and reduction processes. Since both $\mathrm{H}^{+}$ and $\mathrm{OH}^{-}$ions participate in plasma-initiated redox reactions, their concentration in the solution changes with treatment time [23]. Therefore, the acidity of the as- 
treated solution, as well as redox potentials, will also change with treatment time. The plasma treatment of distilled water reduces its $\mathrm{pH}$ to a level $2-3$ that can be explained by the accumulation of hydrogen polyoxides which have acidic properties [23].

Also, the plasma forms nitric oxides $\left(\mathrm{NO}_{\mathrm{x}}\right)$ in nitrogen/oxygen-rich environments, such as air. They dissolve in the solution to form nitrous $\left(\mathrm{HNO}_{2}\right)$ and nitric $\left(\mathrm{HNO}_{3}\right)$ acid which also lowers $\mathrm{pH}$ [24].

In the solution with different $\mathrm{pH}$, different ways of peroxide formation are operative [22] and, thus, the rate of $\mathrm{H}_{2} \mathrm{O}_{2}$ formation is sensitive to the $\mathrm{pH}$ index. In alkaline solutions, the $\mathrm{H}_{2} \mathrm{O}_{2}$ yield is usually much lower than that in neutral or acidic mediums [25]. Being a weak acid, $\mathrm{H}_{2} \mathrm{O}_{2}$ is intensively consumed by reacting with $\mathrm{OH}^{-}$to form $\mathrm{HO}_{2}^{-}$that causes a rather low $\mathrm{H}_{2} \mathrm{O}_{2}$ yield:

$$
\mathrm{H}_{2} \mathrm{O}_{2}+\mathrm{OH}^{-} \rightarrow \mathrm{HO}_{2}^{-}+\mathrm{H}_{2} \mathrm{O}
$$

\subsection{Effect of the Discharge Current of Peroxide Formation}

Depending on discharge type, the yield of $\mathrm{H}^{*}$ and $\mathrm{OH}^{*}$ radicals fluctuates in a rather narrow range 3-8 [20] or $7.6-10 \mathrm{~mol} / \mathrm{F} \mathrm{[18]}$. The initial yield of peroxide was estimated to be close to $\sim 1.5 \mathrm{~mol} / \mathrm{F}$ [20]. However, the concentrations of peroxide vary in a rather broad range. That indicated that the rate of peroxide degradation is sensitive to the solution type and may differ by almost two orders of magnitude even for similar types of the discharge.

The analysis of experimental and literature data $[13,18,26,27]$ suggests that the rate of formation of peroxide depends on the type of discharge, its polarity, and, as a rule, increases with increasing discharge current. There is also some evidence that the material of cathode influences the chemical reactions in the solution via catalytic effects of emitted ions [28]. Such dependencies are easily observed by treating distilled water when the presence of solute compounds does not affect the rate of peroxide release.

During first minutes of plasma treatment, the peroxide concentration $\left(C_{\mathrm{H} 2 \mathrm{O} 2}\right)$ exhibits a linear dependence of treatment time $t$. Therefore, the slope angle $d C_{\mathrm{H} 2 \mathrm{O} 2} / d t$ in coordinates $C_{\mathrm{H} 2 \mathrm{O} 2}=f(t)$ can be used as a measure of the rate of peroxide formation. The dependences of $d C_{\mathrm{H} 2 \mathrm{O} 2} / d t$ on the discharge current are shown in Fig. 4 for different plasma types and configurations. As is seen, the experimental curves are divided into three clusters and thus clearly illustrate the effectiveness of one or another type of discharge relative to the formation of peroxide.

The glow discharge exhibits the highest peroxide formation rates and the most pronounced dependence on the current while the frontal discharge is the least effective in both parameters. Similar results were discussed in [29]. Discharge with water as a cathode is usually much more efficient for $\mathrm{H}_{2} \mathrm{O}_{2}$ production as is seen from Fig. 4 and reported in many researches [30, 31]. When liquid acts as an anode, the cathode voltage fall is formed on the metallic electrode, and the charged particles are electrons entering the anodic solution [25]. Thus, no sputtering and field-induced ion emission takes place at the liquid surface. Evaporation is the only way to transfer water molecules from the liquid phase into the gaseous plasma resulting in a low $\mathrm{H}_{2} \mathrm{O}_{2}$ yield. Higher energy of $\mathrm{OH}^{\circ}$ radicals excited by an intensive electron flux in the configuration with a liquid anode may also cause their quicker decay and thus suppress the rate of peroxide production.

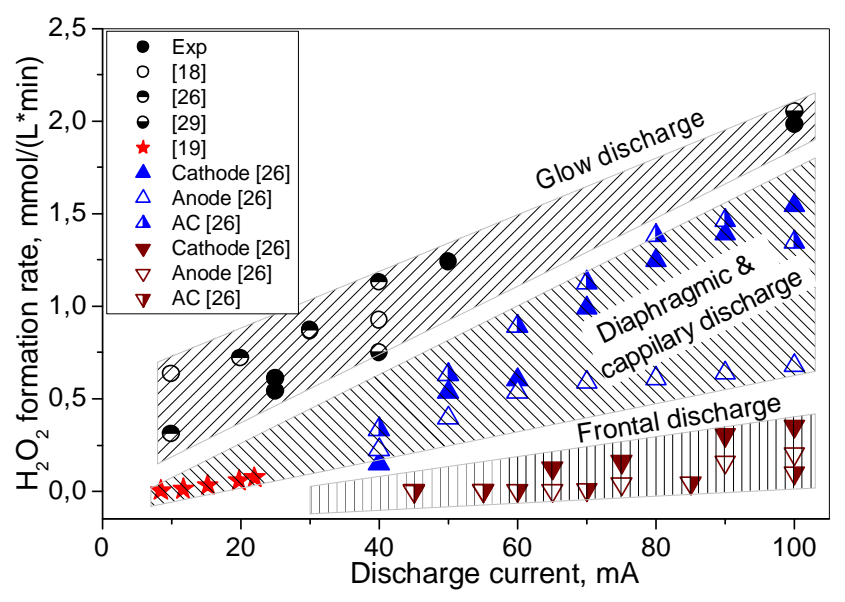

Fig. 4. The rate of $\mathrm{H}_{2} \mathrm{O}_{2}$ formation $\left(d C_{\mathrm{H}_{2} \mathrm{O} 2} / d t\right)$ as a function of discharge current for different plasma configurations: dots glow discharge by various authors, triangles up - diaphragmic discharge in cathode, anode and AC configurations, triangles

down - frontal discharge in cathode, anode and AC configurations, stars - AC capillary discharge

\subsection{Plasma-Induced Redox Reactions}

The experimental results obtained, in particular, changing the oxidation state of metals, show that the plasma treatment initiates both oxidation and reduction processes with participation of ions that contain $\mathrm{Fe}, \mathrm{Mn}$ and $\mathrm{Cr}$. Some redox processes observed in the given paper and other reports are listed in Table 2. Both oxidation and reduction reactions are possible in the considered solution under the action of plasma discharge, as follows from Table 2. Their direction, as well as intensity, depend on many factors, including $\mathrm{pH}$, the concentration of components, discharge type and modes. Evidently, an essential stage of technological applications is the optimisation of the modes and type of discharge. Optimal conditions are dependent on application field. 
As was stated before, peroxide molecules formed in the course of plasma treatment in the solution play an important role in redox processes. This statement is evidenced by the correlations observed between concentrations of peroxide (Fig. 5) and Mn-containing ions (Fig. 1a). As is seen the peroxide appears in the solution after a certain time-delay which increases from approximately 4 to $10 \mathrm{~min}$ with increasing $\mathrm{Mn}$ concentration from 150 to $336 \mu \mathrm{mol} / \mathrm{l}$.

The anticipated sequence of chemical transformations is as follows:

$$
\mathrm{Mn}(\mathrm{VII}) \rightarrow \mathrm{Mn}(\mathrm{VI}) \rightarrow \mathrm{Mn}(\mathrm{IV}) \rightarrow \mathrm{Mn}^{2+}
$$

Several methods, namely: titrimetric (permanganatometric and iodometric) and spectrophotometric (formation of complex compounds with titanium) have been used to determine the content of hydrogen peroxide. For solutions containing $\mathrm{KMnO}_{4}$, the use of both titrimetric methods yields different curves for the $\mathrm{H}_{2} \mathrm{O}_{2}$ concentration as a function of plasma treatment time
(Fig. 5). The possible explanation for this fact is that both titrimetric methods may not be selective for $\mathrm{H}_{2} \mathrm{O}_{2}$ in the presence of other oxidising and reducing particles in the system. Then, the curve obtained from the results of iodometric titration can show the presence of other oxidising particles that are formed both under the influence of the plasma and in the process of redox reactions with hydrogen peroxide. The $\mathrm{H}_{2} \mathrm{O}_{2}$ curves obtained by spectrophotometry and permanganatometric titration coincide. Therefore, these two methods more adequately characterise the presence of $\mathrm{H}_{2} \mathrm{O}_{2}$ in the system.

Reducing particles enter into a reaction with $\mathrm{Mn}(\mathrm{VII})$-containing ions, and they cannot be detected until all $\mathrm{Mn}(\mathrm{VII})$ have reacted. The curves in Fig. 5 support this conclusion: an apparent time delay is observed at both parmanganatometric and spectrophotometric curves, and the duration of the delay increases with the Mn concentration.

Table 2

Redox processes in aqueous solutions with $\mathrm{Mn}, \mathrm{Cr}$ and $\mathrm{Fe}$ caused by plasma treatment

\begin{tabular}{|c|c|c|c|}
\hline Process & Transformations & Medium & Reference \\
\hline Oxidation & $\mathrm{Mn}^{2+} \rightarrow \mathrm{MnO}_{2}$ & Neutral, acid & Experiment, [32] \\
\hline Reduction & $\mathrm{MnO}_{4} \rightarrow \mathrm{MnO}_{2}$ & Neutral, acid & {$[32]$} \\
\hline Reduction & $\mathrm{MnO}_{4}-\rightarrow \mathrm{MnO}_{2}$ & Alkaline & {$[33]$} \\
\hline Reduction & $\mathrm{MnO}_{4}^{-} \rightarrow \mathrm{MnO}_{2} \rightarrow \mathrm{Mn}^{2+}$ & Neutral, acid & Experiment \\
\hline Oxidation & $\mathrm{Fe}^{2+} \rightarrow \mathrm{Fe}^{3+}$ & Acid & Experiment, [32] \\
\hline Oxidation & $\mathrm{Fe}^{2+} \rightarrow \mathrm{Fe}(\mathrm{OH})_{3}$ & Neutral & Experiment, \\
\hline Oxidation of the central ion & {$\left[\mathrm{Fe}(\mathrm{CN})_{6}\right]^{3-} \rightarrow \mathrm{Fe}\left[\mathrm{Fe}(\mathrm{CN})_{6}\right]$} & Neutral & {$[32]$} \\
\hline Reduction & $\mathrm{Cr}_{2} \mathrm{O}_{7}^{2-} \rightarrow \mathrm{Cr}_{2} \mathrm{O}_{3}$ & Neutral & {$[32]$} \\
\hline Oxidation & $\mathrm{Cr}^{3+} \rightarrow \mathrm{Cr}_{2} \mathrm{O}_{6}{ }^{2-}$ & Neutral, acid & {$[32]$} \\
\hline Reduction & $\mathrm{Cr}_{2} \mathrm{O}_{7}^{2-} \rightarrow \mathrm{Cr}^{3+}$ & Neutral, acid & Experiment \\
\hline Reduction & $\mathrm{CrO}_{4}{ }^{2-} \rightarrow \mathrm{Cr}^{3+}$ & Neutral, acid & Experiment \\
\hline
\end{tabular}
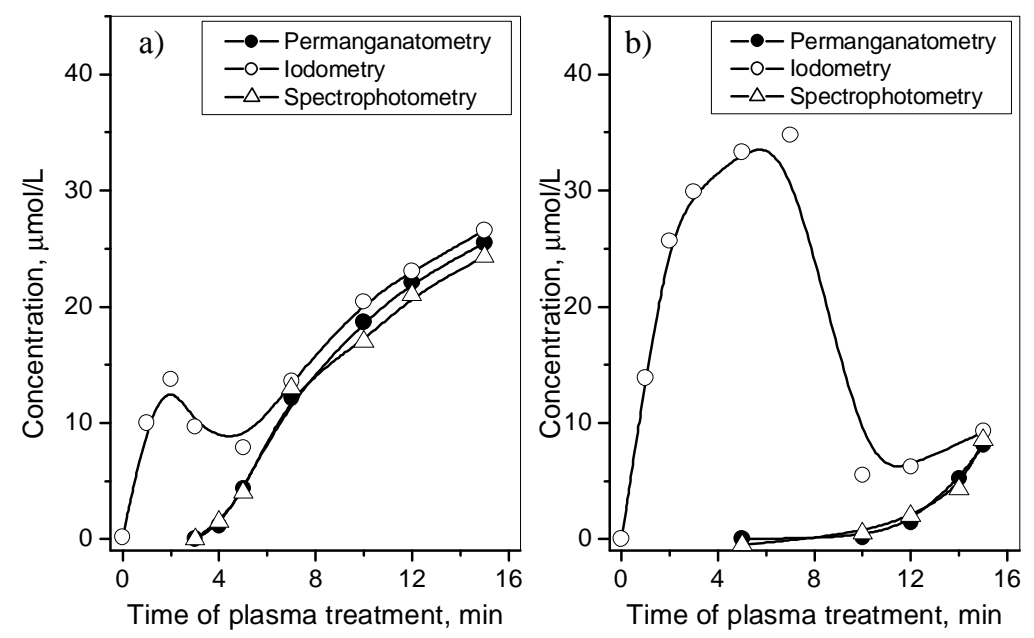

Fig. 5. Concentrations of oxidising compounds and peroxide, determined

by permanganatometry (black dots), iodometry (open dots) and spectrophotometry (triangles), in aqueous solutions of $\mathrm{KMnO}_{4}$ with $150 \mu \mathrm{mol} / \mathrm{l} \mathrm{Mn}$ (a) and $336 \mu \mathrm{mol} / \mathrm{l} \mathrm{Mn}$ (b) as a function of plasma treatment time 
After reduction of manganese to $\mathrm{Mn}^{2+}$, an excess of reducing particles reacts with oxidising particles. Such a reaction results in a temporal decrease of the total concentration of oxidising compounds at a particular stage of plasma treatment as is illustrated by the iodometric curves in Fig. 5.

Later, redox processes tend to their completion, and the rate of consumption of both reducing and oxidising particles diminishes. As a result, accumulation of these particles is resumed in the solution. Hydrogen peroxide is then determined both iodometrically and permanganatometrically/spectrophotometrically. At this stage, all the above methods give close values of the peroxide concentration.

\section{Conclusions}

Aqueous solutions of various compounds containing $\mathrm{Mn}, \mathrm{Fe}$ and $\mathrm{Cr}$ were treated by a low-pressure glow discharge. The discharge conditions, such as polarity, discharge current and air pressure, were preliminary optimised regarding increasing the effectiveness of its influence on the redox processes. The concentration of peroxide, as well as the concentration and oxidation level of metals in the as-treated solutions, were studied as a function of treatment time.

The effect of plasma treatment of manganese permanganate solutions consists in the reduction of $\mathrm{Mn}(\mathrm{VII})$ first to $\mathrm{Mn}(\mathrm{IV})$ and then to $\mathrm{Mn}(\mathrm{II})$. Hydrogen peroxide is generated under the plasma action but is initially expended in reducing the Mn-containing ions. When the redox processes diminish, $\mathrm{H}_{2} \mathrm{O}_{2}$ molecules accumulate in the solution.

In ferrous solutions, the oxidation of $\mathrm{Fe}(\mathrm{II})$ to $\mathrm{Fe}(\mathrm{III})$ ions occurs under the action of plasma. If $\mathrm{pH}$ of the solution is less than 2 (strong-acidic medium), the transformation of $\mathrm{Fe}$ (II) to $\mathrm{Fe}$ (III) is almost complete, and the total content of iron ions does not change in the solution. If $\mathrm{pH}$ is higher than the value mentioned above, the oxidation process is also completed, but the total concentration of $\mathrm{Fe}$ in solution is reduced because of partial precipitation. In solutions with $\mathrm{Fe}(\mathrm{III})$, the plasma discharge does not change the oxidation level of Fe.

In solutions of chromium compounds, the reduction of $\mathrm{Cr}(\mathrm{VI})$ to $\mathrm{Cr}(\mathrm{III})$ is observed in an acidic medium. The value of $\mathrm{pH}$ index reduces from 6-8 to 2.8 concurrently with the $\mathrm{Cr}$ reduction. The oxidation level of metal does not change under the plasma action in solutions that contain $\mathrm{Cr}(\mathrm{IIII})$.

The action of a plasma discharge results in the acidification of the treated medium. Such a phenomenon was observed in all $\mathrm{Cr}$ - and $\mathrm{Mn}$-containing solutions and was less-pronounced in solutions of Fe compounds.
The concentration of hydrogen peroxide formed under the plasma discharge was measured by titrimetric (permanganatometric and iodometric) and spectrophotometric methods. The permanganatometry and spectrophotometry allowed to estimate the amount of hydrogen peroxide molecules which act as reducing agents. The results of iodometric measurements described the total concentration of all oxidisers.

The concentration of hydrogen peroxide usually increases with treatment time, but it is not detected during active redox interaction with metal-containing ions. In general, the curves characterising the change in the ion concentrations with metals of different oxidation level correlate well with the curves describing the hydrogen peroxide formation.

\section{References}

[1] Ishijima T., Nosaka K., Tanaka Y. et al.: Appl. Phys. Lett., 2013, 103, 142101. https://doi.org/10.1063/1.4823530

[2] Vorobyova M., Pivovarov O.: Voprosy Khim. Khim. Tekhnol., 2014, 3, 19.

[3] Mariotti D., Sankaran R. et al:: J. Phys. D, 2011, 44, 174023. https://doi.org/10.1063/1.4823530

[4] Smoluch M., Mielczarek P., Silberring J.: Mass Spectrom. Rev., 2016, 35, 22. https://doi.org/10.1002/mas.21460

[5] Chmilenko F., Derkach T., Smityuk A.: J. Anal. Chem., 2000, 55, 327. https://doi.org/10.1007/BF02757765

[6] Chmilenko F., Pivovarov A., Derkach T. et al.: J. Anal. Chem., 1997, 52, 311.

[7] Fridman G., Friedman G., Gutsol A. et al.: Plasma Proc. Polym., 2008, 5, 503. https://doi.org/10.1002/ppap.200700154

[8] Jiang B., Zheng J., Qiu S. et al.: Chem. Eng. J., 2014, 236, 348. https://doi.org/10.1016/j.cej.2013.09.090

[9] Misra N.: Trends Food Sci. Tech., 2015, 45, 229. https://doi.org/10.1016/j.tifs.2015.06.005

[10] Magureanu M., Piroi D., Mandache N. et al.: Water Research, 2010, 44, 3445. https://doi.org/10.1016/j.watres.2010.03.020

[11] Shutov D., Isakina A., Konovalov A. et al.: High Energ. Chem., 2013, 47, 201. https://doi.org/10.1134/S0018143913040115 [12] Bobkova E., Krasnov D., Sungurova A. et al.: Korean J. Chem. Eng., 2016, 33, 1620. https://doi.org/10.1007/s11814-015-0292-7

[13] Choukourov A., Manukyan A., Shutov D. et al.: Izv. Vyssh. Uchebn. Zaved. Khim. Khim. Tekhnol., 2016, 59, 4. https://doi.org/10.6060/tcct.20165912.5413

[14] Ramli N., Zaaba S., Mustaffa M. et al.: AIP Conf. Proc., 2017, 1824, 030015-1. https://doi.org/10.1063/1.4978833

[15] Brisset J.-L., Moussa D., Doubla A. et al.: Ind. Eng. Chem. Res., 2008, 47, 5761. https://doi.org/10.1021/ie701759y

[16] Jiang B., Guo J., Wang Z. et al.: Chem. Eng. J., 2015, 262, 1144. https://doi.org/10.1016/j.cej.2014.10.064

[17] Pivovarov O., Zakharov R., Nikolenko M.: Chem. Chem. Technol., 2015, 9, 95. https://doi.org/10.23939/chcht09.01.095 [18] Bobkova E., Shikova T., Grinevich V. et al.: High Energ. Chem., 2012, 46, 56. https://doi.org/10.1134/S0018143912010079 [19] De Baerdemaeker F., Simek M., Leys C.: J. Phys. D, 2007, 40, 2801. https://doi.org/10.1088/0022-3727/40/9/021

[20] Maksimov A., Khlyustova A.: High Energ. Chem., 2009, 43, 149. https://doi.org/10.1134/S0018143909030011 
[21] Zhao Y., Wang T., Wilson M. et al.: IEEE Transact. Plasma Sci., 2016, 44, 2084. https://doi.org/10.1109/TPS.2016.2547841

[22] Pivovarov A., Kravchenko A., Tishchenko A. et al.: Russ. J. Gen. Chem., 2015, 85, 1339.

https://doi.org/10.1134/S1070363215050497

[23] Pivovarov A., Nikolenko N., Zakharov R. et al.: Voprosy Khim. Khim. Tekhnol., 2012, 3, 127.

[24] Go D.: J. Phys. Conf. Series, 2015, 646, 012052.

https://doi.org/10.1088/1742-6596/646/1/012052

[25] Liu J., He B., Chen Q. et al.: Sci. Rep., 2016, 6, 38454.

https://doi.org/10.1038/srep38454

[26] Silkin S.: Elektronnaya Obrabotka Mater., 2014, 50, 106.

[27] Pivovarov A., Zakharov R., Nikolenko N.: Voprosy Khim.

Khim. Tekhnol., 2013, 3, 174.

[28] Kuz'micheva L., Titova Yu., Maksimova A. et al.: Surf. Eng. Appl. Electrochem., 2013, 49, 485.

https://doi.org/10.3103/S1068375513060100

[29] Kuz'micheva L., Titova Yu., Maksimova A.: Elektronnaya Obrabotka Mater., 2007, 2, 20.

[30] Xiong R., Nikiforov A., Vanraes P. et al.: J. Adv. Oxid.

Technol., 2012, 15, 197. http://hdl.handle.net/1854/LU-2125069

[31] Miyahara T., Oizumi M., Nakatani T. et al.: AIP Adv., 2014, 4, 047115. https://doi.org/10.1063/1.4871475

[32] Kutepov A., Zakharov A., Maksimov A., Titov V.: High Energ. Chem., 2003, 37, 317. https://doi.org/10.1023/A:1025704930260
[33] Kuz'micheva L., Maksimova A., Titova Yu.: Elektronnaya Obrabotka Mater., 2005, 5, 47.

Received: February 24, 2018 / Revised: March 31, 2018 / Accepted: June 12, 2018

\section{ОБРОБЛЕННЯ ПЛАЗМОВИМ РОЗРЯДОМ ПОНИЖЕНОГО ТИСКУ ВОДНИХ РОЗЧИНІВ, ЩО MICTЯTb Mn, Cr TA Fe}

\footnotetext{
Анотація. Досліджено вплив тліючого розряду пониженого тиску на утворення гідроген пероксиду та зміну ступеню окиснення металів у водних розчинах сполук $\mathrm{Mn}, \mathrm{Cr}$ ma Fe. Показано, щуо плазмове оброблення спричиняє відновлення $\mathrm{Mn}(\mathrm{VII})$ через $\mathrm{Mn}(\mathrm{IV})$ до $\mathrm{Mn}(\mathrm{II}), \mathrm{Cr}(\mathrm{VI})$ до $\mathrm{Cr}(\mathrm{III}) \mathrm{ma}$ окиснення $\mathrm{Fe}(\mathrm{II})$ до $\mathrm{Fe}(\mathrm{III})$. Гідроген пероксид, що утворюється під дією плазмового оброблення, активно бере участь в окисновідновних реакиіях. Кониентрачія гідроген пероксиду зазвичай збільшується з часом оброблення, однак виявити його наявність стає можливим тільки після закінчення перебігу активних окисно-відновних прочесів.

Ключові слова: оброблення плазмовим розрядом пониженого тиску, окисно-відновні реакиії, утворення гідроген пероксиду, відновлення, окиснення.
} 